\title{
Impressão estética e experiência como diretriz de projeto de objetos de ensino- aprendizagem
}

\author{
Aesthetic impression and experience as a guideline to design e-learning objects
}

\author{
Tobias T. Mülling, Alice C. Pereira
}

impressão estética, hipermídia, educação à distância

\begin{abstract}
O design, dentro de sua essência, possui a estética como instrumento de criação e avaliação; a estética, na hipermídia, é fator decisivo na experiência do usuário. O julgamento de interfaces sob a ótica da impressão estética é responsável por parte do processo de engajamento do usuário em um ambiente hipermidiático. Este artigo aborda o desenvolvimento de uma hipermídia de aprendizagem para o projeto Formação continuada de conselheiros municipais de educação - MEC - que destina-se a conselheiros municipais de todo Brasil, como parte de sua formação continuada. Para o desenvolvimento do ambiente, foram utilizados conceitos relacionados à impressão estética como suporte para o design da informação, visto que é o primeiro impacto do aluno (conselheiro) com a hipermídia, associado a noções de projeto com relação à experiência do usuário.
\end{abstract}

aesthetical impression, hypermedia, e-learning

The design, in its essence, has aesthetics as a creation and evaluation tool, which in hypermedia consists of an important factor in the user experience. The evaluation of interfaces from an aesthetic impression is responsible for part of the user's engaging process in a hypermediatic environment. This paper focuses on the development of a learning hypermedia for the Project "Continued preparation for city education counselors MEC", which is planned for city counselors all over Brazil, as part of their continued professional preparation. In order to have the environment build up, concepts related to aesthetical impression as support for information design were used, since it is the first contact of the student (counselor) with hypermedia, associating ideas of project with the experience of the user.

\section{Introdução}

O design de hipermídia é caracterizado pela hibridização de meios, e, em sua síntese, ocorre a partir da junção entre a multimídia e o hipertexto, destacando-se pelas tomadas de decisão do usuário frente ao meio que lhe é proposto. Paralelamente o design, como área de atuação, possui a estética como um de seus principais instrumentos de avaliação e criação, associado principalmente à beleza. Por estar inserido dentro do design como área de atuação, o design de hipermídia apropria-se deste importante conceito como uma estratégia para compreensão e aceitação das interfaces pelo usuário. Dentre estas possibilidades, surge o design de experiência que, associado à estética, se propõe a criar não apenas produtos, mas experiências de fruição dos sistemas hipermidiáticos.

A experiência do usuário é a forma como o produto se comporta e é usado no mundo real, ou seja, além de atentar para as funcionalidades e recursos, também se deve perceber como será o contato do usuário com o produto. (Garret 2003:7)

O design de experiência tem como premissa a satisfação do usuário, relacionado ao seu repertório, suas experiências anteriores. Shedroff (2001:14) cita que todas as experiências são importantes, sejam off-line, digitais ou outra experiência tecnológica. Com base nestas experiências, deve ser definida a estratégia que deverá ser utilizada para engajar este usuário, ocasionando a experiência.

Este artigo se propõe a demonstrar a utilização da impressão estética e do design de experiência como apoio ao design de informação, através do desenvolvimento de um objeto de ensino-aprendizagem, utilizado na educação à distância. Este objeto compreende a geração de hipermídias de conteúdo para o projeto Formação continuada de Conselheiros Municipais de Educação (CME).

InfoDesign | Revista Brasileira de Design da Informação / Brazilian Journal Information Design v. 6 | n. 3 [2009], p. 38 - 49 | ISSN 1808-5377 


\section{Projeto Formação continuada de Conselheiros Municipais de Educação (CME)}

O Programa Nacional de Capacitação Continuada de Conselheiros Municipais de Educação está inserido em um contexto singular e estratégico do processo de gestão democrática da política educacional formulada pelo atual Governo. A proposta de um ambiente hipermídia visa a constituir a seção destinada ao conteúdo, como objeto de ensino-aprendizagem. O projeto como um todo se caracteriza pela instituição de um AVEA (Ambiente Virtual de Ensino-Aprendizagem), cujo usuário poderá acessar, através deste ambiente, os objetos de ensino-aprendizagem relatados neste artigo.

A formação dos conselheiros constitui uma iniciativa que busca assegurar que os Conselhos Municipais de Educação se tornem uma instância efetiva de decisão, fiscalização e normatização das práticas educacionais, constituindo assim um lócus de mediação significativa entre a sociedade e o poder público. Nesta perspectiva, este projeto de formação procura atuar no desenvolvimento profissional dos conselheiros, visando assegurar sua participação crítica nos diferentes âmbitos de suas atividades profissionais.

A formação deve desenvolver-se na modalidade a distância, cuja característica principal é a ênfase em processos abertos de aprendizagem, caracterizados pela flexibilidade na organização do currículo e do ensino; pelo incentivo à autonomia intelectual do indivíduo e pelo elevado grau de interação entre os participantes por meio das Tecnologias de Informação e Comunicação. A Educação a Distância (EaD) caracteriza-se ainda pelo seu alcance tanto do ponto de vista espacial quanto do ponto de vista temporal. Ou seja, pelo seu potencial em atingir populações distantes, o que possibilita uma diversidade destas populações, e por propiciar uma flexibilidade de tempo, 0 que possibilita o acesso a um público que mantém seus vínculos locais.

Os objetos de ensino-aprendizagem desenvolvidos compreendem os seguintes módulos:

1. Educação a distância;

2. Concepção, estrutura e funcionamento dos $\mathrm{CME}$;

3. Funções dos CME e suas articulações com as políticas públicas;

4. Projeto integrador.

Dentro desta proposta, foram desenvolvidos os presentes módulos de conteúdo utilizando-se de tecnologias que possibilitam o uso de uma série de elementos de comunicação para a interação, potencializando o ensino e a aprendizagem à distância.

\section{Impressão estética}

Definida, segundo Crilly et al. (2004), como a sensação que resulta da percepção de atratividade (ou não atratividade) nos produtos. A palavra estética é derivada do grego aesthesis, e seu significado está relacionado à percepção sensorial. De fato, a impressão estética advém da resposta cognitiva do usuário; esta refere-se aos julgamentos que o usuário faz sobre determinado produto a partir da informação percebida através dos sentidos, principalmente a visão. A resposta cognitiva pode ser dividida em três categorias: impressão estética, interpretação semântica e associação simbólica. No entanto, para o presente trabalho, será abordada apenas a impressão estética, devido ao foco do mesmo.

A impressão estética, sob o ponto de vista empírico, "caracteriza" o trabalho de um designer, visto que estudos sobre beleza têm defendido a perspectiva de que a característica da atratividade reside no próprio objeto. Os produtos que se destacam dos seus concorrentes, geralmente, são os que possuem uma boa aparência visual. A marca também é um fator importante, mas se o produto não induz uma impressão estética satisfatória, dificilmente provocará a atração necessária para o consumidor realizar a compra. Nos websites, a impressão estética talvez seja ainda mais importante, pois o usuário pode se desfazer do produto rapidamente e procurar um concorrente em poucos segundos. Crilly et al. (2004) ratificam esta afirmação:

A aparência visual dos produtos é um determinante crítico da resposta do consumidor do sucesso do produto. Julgamentos são muitas vezes feitos sobre a elegância, funcionalidade e significado social dos produtos baseados em grande parte na informação visual. Estes julgamentos relatam os atributos percebidos dos produtos e freqüentemente centram-se na satisfação do consumidor em relação ao que ele quer e deseja, mais do que o que ele necessita.

Embora a estética tenha sido estudada ao longo do tempo, ainda não existe um consenso universal sobre julgamentos a respeito do bonito/feio, devido a sua subjetividade. Crozier (apud 
Crilly et al. 2004) sugere que a presença de diferenças entre os julgamentos das pessoas torna difícil acreditar em princípios estéticos universais e que respostas inerentes podem ser ilusão. Isto porque a impressão estética também está relacionada a fatores sócio-culturais, econômicos e tecnológicos. No entanto, existem princípios tais como a Gestalt, que estabelece regras como simetria, proximidade, entre outras regras destinadas à composição. Lobäch (2001) pondera que a tradicional expressão "Este site eu acho bonito, ou este me agrada mais..." se baseia nas idéias de valor de uma pessoa, e estes juízos estéticos são relacionadas à medida do prazer estético proporcionado pela aparência visual do website no usuário.

O julgamento sobre a impressão estética de um website/produto está diretamente associado à forma. Esta, atua como elemento organizador, e serve de suporte ao conteúdo. Bonfim (apud Pirauá, 2007) destaca:

(...) Um produto é uma unidade entre forma e conteúdo. O conteúdo se refere aos aspectos "internos" do objeto, isto é, aos elementos e relacionamentos que caracterizam sua natureza. A forma é o "externo" dos objetos, ou seja, a estrutura visível, resultante de elementos como cor, superfície, proporções, textura, etc. Forma e conteúdo são indivisíveis (...)

A forma compreende o primeiro contato visual de um website em seu usuário, responsável pela atração inicial, e o conteúdo responde pelo engajamento do usuário relacionado à seu processo de experiência em um website. Sobre esta experiência, Garret (2003) determina planos conceituais para o desenvolvimento de websites. A estética enquadra-se no último processo de desenvolvimento sugerido pelo autor, o plano de superfície. Nesta etapa, é executado o design visual (ou gráfico), responsável pela impressão estética que o usuário obterá em sua experiência. É importante destacar que o design visual representa todas as etapas anteriores de construção de um website, como concepção, arquitetura de informação, etc. Portanto, o sucesso da experiência do usuário não está atrelado apenas ao design visual, mas a todo o processo de construção da experiência do usuário (intrínseco ao design de informação).

\subsection{Experiência estética}

O contato do usuário para com a interface consiste no primeiro passo para que ocorra a experiência. Sustentado por esta afirmação, Ribeiro (2006 apud Pirauá, 2007) argumenta que a interface visualmente atrativa e agradável aos sentidos é algo obrigatório em sites que valorizam a experiência. A estética possui uma grande influência sobre o comportamento do sujeito, e sua percepção. Portanto a experiência estética é, como mencionado no design de experiência, algo individual, relacionado ao sujeito.

Pode-se entender, portanto, que a experiência estética não está no objeto, ou naquele que observa o objeto, e, sim, no efeito causado pelo objeto sob a percepção do indivíduo, ou seja, a experiência estética (e conseqüentemente a beleza) reside na relação entre sujeito e objeto. Defendemos que, assim como na experiência estética, nos fenômenos estéticos de menor intensidade é sempre a relação entre sujeito e objeto que é determinante. Isto porque sujeito e objeto são variáveis de modo que um mesmo objeto pode causar diferentes reações até mesmo em pessoas semelhantes. (Pirauá, 2007:18)

Como parte fundamental desta experiência estética, Lobäch (2001) descreve que as relações designer - produto e as relações usuário produto constituem processos dinâmicos, e estes fazem parte de uma comunicação estética entre o designer e o usuário. Sob estas definições, das relações entre usuário (sujeito) e produto (objeto), por meio da comunicação, surge a experiência estética. Neste percurso, Lobäch (2001) propõe um diagrama tomando como base o esquema da teoria da informação no qual temos: emissor, mensagem e receptor, mas fazendo uma analogia à esta teoria, em que o designer é o emissor, o produto (website) é a mensagem e o receptor é o usuário. Com isto, surge uma divisão estética nos seguintes itens: 
Figura 1: Comunicação estética (Lobäch, 2001)

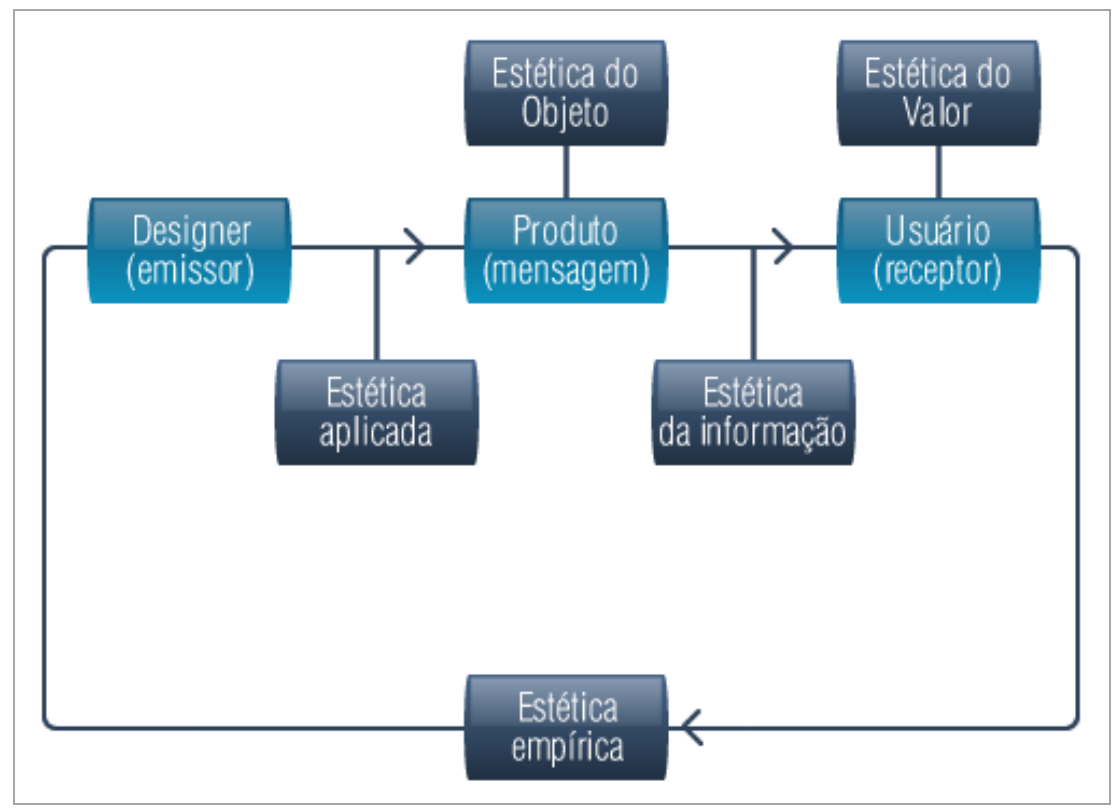

1. Estética do objeto: está relacionada à descrição das características formais dos objetos;

2. Estética do valor: diz respeito à importância das formas para os usuários como parte de um sistema sociocultural;

3. Estética aplicada: é a aplicação da teoria estética na prática, abrange tanto a produção estética quanto o processo de design;

4. Estética da informação: corresponde ao processo de consumo visual dos objetos, ou seja, à percepção da estética do objeto enquanto informação;

5. Estética empírica: é a realização de pesquisas sobre os valores estéticos dos usuários para melhoria do processo de design.

Podemos verificar que a estética influencia no design de diversas formas, através desta categorização. Dentre essas divisões, também é importante destacarmos a percepção. Lobäch (2001) a define como um processo pelo qual a aparência estética se transforma em significado. É um processo subjetivo que, às vezes, é influenciado pela imagem atual da percepção, mas também pela memória de cada pessoa, como experiências anteriores, conceitos de valor e norma socioculturais.

Através da percepção, o usuário engaja-se no processo de experiência do website; é interessante, no entanto, que a aparência de um produto é projetada para consumidores em massa, ou grupos de usuários, mas a experiência ocorre de maneira distinta para cada usuário. Esta preocupação frente ao problema de "o que devo criar para o usuário", vem de encontro à definição de design de Lobäch. Segundo o autor, design é o processo de adaptação do ambiente 'artificial' às necessidades físicas e psíquicas dos homens na sociedade. $O$ processo de "adaptação" de um website (ou a experiência) ocorre em virtude das necessidades e possibilidades criadas ao usuário, associadas ao design da informação. O design de um website, como processo, não compreende apenas a experiência estética, mas também os aspectos funcionais e simbólicos. No entanto, um usuário dificilmente voltará a um website que julgue feio. Sob esta perspectiva, a estética obtém seu objetivo, e também desafio frente às interfaces.

\subsection{Equilíbrio estético}

Este termo, utilizado por Crilly et al. (2004), converge para as relações do usuário em relação à impressão estética. Se um website possui pouca atratividade, resultará na indiferença; por outro lado, caso evoque em um grau extremo a atenção do usuário, poderá causar desagrado. A estética da informação, mencionada anteriormente por Lobäch (2001), enquadra-se nesta classificação, onde analisa a estética do ponto de vista da informação como objeto. Nesta informação estão contidos dados relacionados à forma, conteúdo, composição, subjetividade, características inerentes ao produto (website). 
Este balanceamento estético é descrito por Coates (apud Crilly et al. 2004), como uma harmonia entre dois fatores: informação e concisão. A informação se relaciona tanto com a inovação como com o contraste, que pode servir para despertar o interesse do usuário. E de modo inverso, a concisão se relaciona com a ordem e o sentido percebidos em um design, que pode ajudar o consumidor a entender o produto. $\mathrm{O}$ autor ainda classifica estas "medidas harmônicas" em propriedades objetivas e subjetivas:

- Informação Objetiva: é determinado pela forma como certos elementos são combinados. Por exemplo, websites que possuem várias formas, linhas e texturas, irão exibir um alto grau de contraste.

- Informação subjetiva: pode ser associada ao caráter de novidade, inovação. Geralmente, quando um determinado produto (website) difere-se de sua forma usual, despertando o interesse do usuário. Hoje, através da tecnologia, nos deparamos com várias interfaces diferentes, com múltiplas opções de cor, vídeo, 3D, etc.

- Concisão Objetiva: pode ser considerada como a aplicação de princípios já estabelecidos de design, como a Gestalt, por exemplo. Está relacionada a seriedade, com grande utilização de simetria e ortogonalidade, gerando websites racionais e ordenados.

- Concisão Subjetiva: está relacionada ao sentido do design para o espectador. Ela é determinada por valores pessoais, tais como cultura e repertório visual, que auxiliam na compreensão das interfaces.

Portanto, é necessário avaliar se o valor total da informação (objetiva + subjetiva) está em harmonia com a concisão (objetiva + subjetiva). A discrepância de um em relação à outro pode vir a gerar um website sem sentido, feio, ou uma interface simples e fraca do ponto de vista estético.

\subsection{Sintaxe Visual}

Para compreendermos as interfaces, é necessário determinarmos alguns parâmetros, tendo como base uma linguagem visual. Dondis (1991) sugere que uma das melhores formas para compreendermos qualquer obra visual é decompô-la em elementos constitutivos, para compreender-se o todo. Com a finalidade de determinar alguns atributos para avaliação de elementos visuais, definindo uma sintaxe, foram escolhidas categorias para avaliação das interfaces, a partir das categorias definidas por Dondis (1991:34).

- Forma: está relacionado ao gênero da forma, ou seja, circular, quadrado, triangular, e formas decorrentes da combinação destas formas básicas.

- Escala: é a relação entre o tamanho dos elementos. Ou seja, o pequeno não pode existir sem o grande e vice-versa. É utilizado para manter a realidade visual nas imagens.

- Direção: diz respeito à orientação, a partir das formas básicas. O quadrado, a horizontal e a vertical. O círculo, as curvas, e o triângulo, a diagonal.

- Tom: compreende a relação de intensidade entre claro e escuro, entre o contraste de formas. Dondis (1991) ainda afirma que as variações de tom são os meios pelos quais distinguimos oticamente a complexidade da informação visual do ambiente.

- Cor: esta é uma das mais penetrantes experiências visuais que temos todos em comum. Está relacionado às emoções, e pode ser medida em matiz, saturação e brilho. Guimarães (2000) define a cor como uma informação visual, causada por um estímulo físico, percebida pelos olhos e decodificada pelo cérebro.

- Textura: são padrões visuais que se apresentam nas formas. Pode ser percebida sob o tato, e também como textura visual. Em virtude do objeto de estudo, os websites (ainda) não possibilitam as texturas táteis, apenas visuais.

Neste presente trabalho, prentende-se adicionar um item à esta sintaxe visual, que não se encontra presente nos postulados de Dondis.

- Temporalidade: compreende o fator tempo, a partir da avaliação de animações presentes nos websites, e, talvez, fundamentais para a experiência dos mesmos. 


\subsection{Interface}

A interface responde por uma espécie de camada, um instrumento mediador entre o usuário e o website. A partir deste conceito, Johnson afirma:

Mas, afinal, que é exatamente uma interface? Em seu sentido mais simples, a palavra se refere a softwares que dão forma à interação entre usuário e computador. A interface atua como uma espécie de tradutor, mediando entre as duas partes, tornando uma sensível para a outra. (Johnson, 2001:18)

Desta forma, fica claro o papel da interface para com o usuário. A imagem posterior exemplifica a interface em um sistema hipermidiático, onde se propõe a interface como balizadora dos sistemas que a suportam.

Figura 2: A interface frente a um sistema hipermidiático

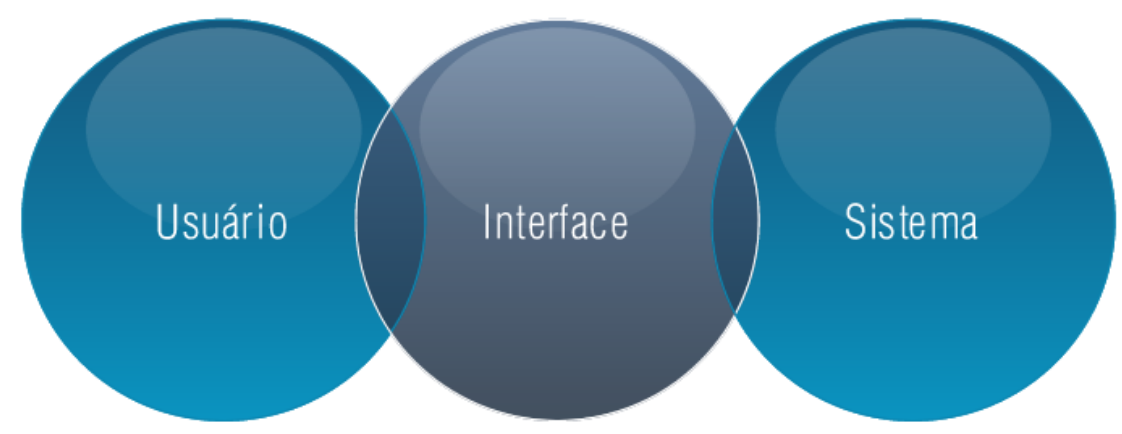

Com a popularização das interfaces, elementos advindos da metáfora do desktop, como janelas, ícones, se tornaram comuns em nosso dia-a-dia. Com isto, os websites atuais se utilizam destes recursos, e incluem diferentes formas de menus, navegação, disposição de elementos, etc, alicerçados nas novas possibilidades tecnológicas e na cognição de um usuário educado sob uma cultura de interface. No entanto, deve-se atentar para que o usuário de determinado website possua repertório suficiente para compreender a interface, a fim perceber o que esta vem a transmitir, proporcionando a interação. A composição desta interface relaciona-se diretamente ao design de informação e ao processo cognitivo do usuário final.

\section{Objeto de ensino-aprendizagem do CME}

A interface, como citado anteriormente, é o elo entre o usuário e o ambiente hipermidiático. No entanto, para existir uma relação entre os mesmos, é necessário a interatividade, responsável pelos atos de decisão do usuário frente à interface. Moura (2006) ainda define que a interação é um processo de controle e resposta (feedback) entre o usuário e o computador, com uma troca de ação entre elementos ativos e o meio através da utilização ou acoplamento de entradas (inputs) e saídas (outputs).

A hipermídia fornece ao usuário ferramentas de interação, possibilitando uma navegação não linear. Por conseguinte, é necessário fazer com que o usuário exerça esta atividade, ou seja, engajar o público. Sobre este pressuposto, Baeta Neves (2006) elenca:

Para comunicar, a hipermídia necessita engajar seu público em sua própria dinâmica de virtualidades.

Sob esta perspectiva, é possível argumentar que, enquanto projeto de design, o projeto hipermidiático

compromete-se com o engajamento de seu público. Trata-se do comprometimento implícito, por exemplo, no intuito de guiar o usuário por determinado caminho entre os elementos audiovisuais da interface ou de prender sua atenção por certo tempo em determinado momento da navegação.

A partir desta afirmação, comprova-se a necessidade do designer frente ao projeto de um objeto de ensino-aprendizagem, de projetar os elementos de interação, sejam eles links presentes no hipertexto, ou novas formas de interatividade, suportadas pela tecnologia atual. Sob esta perspectiva, o design de informação corrobora para a criação e desenvolvimento de objetos de ensino-aprendizagem, aliando-se aos preceitos estéticos que venham de encontro aos interesses do usuário. 
O projeto Formação continuada de Conselheiros Municipais de Educação (CME) utilizou-se de uma metodologia de projeto objetivando a experiência do usuário, a partir de definições relacionadas à concepção, público-alvo, storyboards, wireframes, culminando com o design visual e de informação, onde foi proposta uma estética condizente com os pressupostos mencionados na seção anterior (figura 3).

Figura 3: Objeto de ensino-aprendizagem (Ilustração: Marcel Junges e Bruno Muller)

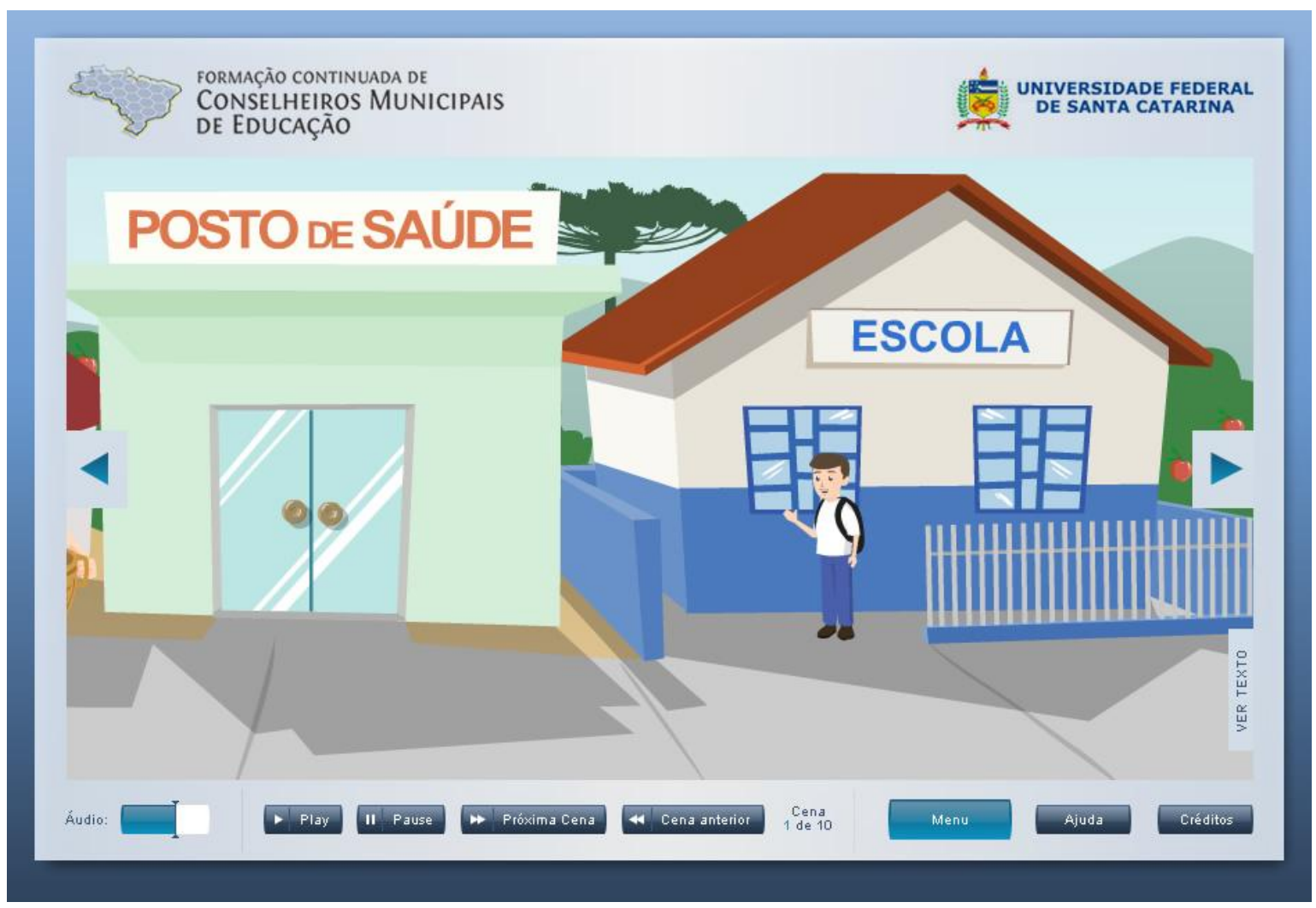

\subsection{Projeto}

Tendo em vista a apresentação do objeto de ensino-aprendizagem, a hipermídia foi projetada sob uma interface, responsável por mediar a interação do usuário, de acordo com recursos que viessem a enriquecer sua experiência e impressão estética.

Este projeto demonstra a importância da relação entre estética e design da informação, culminando em um incremento da experiência do usuário. Conforme fora discutido anteriormente, a estética corresponde à primeira impressão do usuário frente a interface; portanto, esta é intrínseca ao design da informação, visto que está repleta de valores subjetivos e objetivos. 
Figura 4: Projeto CME (Direção de Arte: Tobias Mülling, llustração: Marcel Junges e Bruno Muller)

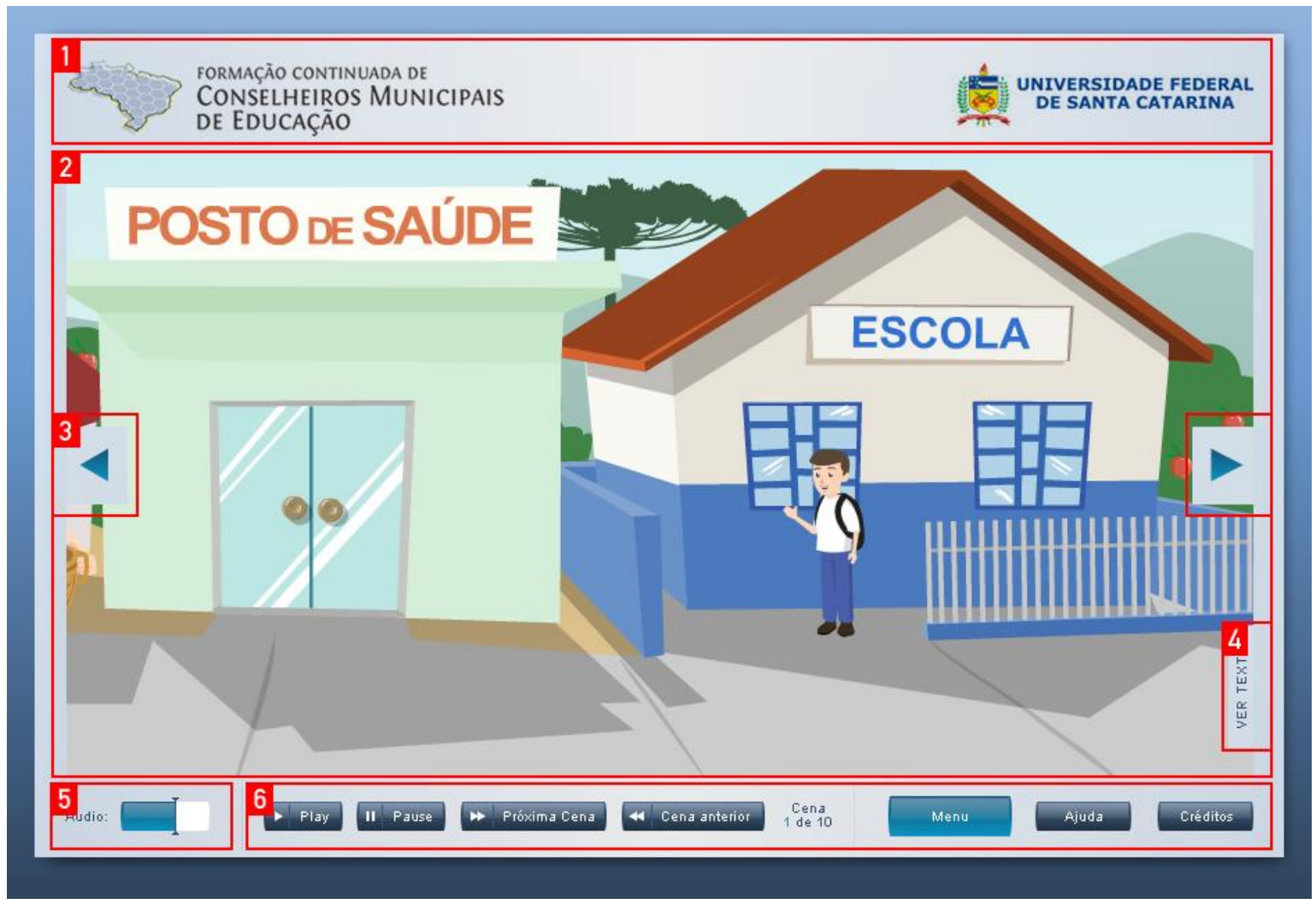

1. Topo - compreende a marca do projeto, juntamente com a marca da Universidade Federal de Santa Catarina. A marca é um componente importante para a experiência do usuário, visto que identifica a hipermídia e traduz e identifica os conselheiros municipais no ambiente digital. Do ponto de vista estético, o topo apresenta-se com a informação disposta claramente, de forma concisa e objetiva.

2. Área de Conteúdo - área definida para apresentar o conteúdo da hipermídia. Este conteúdo compõe-se de animações, que serão discutidas posteriormente.

3. Navegação entre cenas, indicando ao usuário a possibilidade de navegar para a próxima cena ou cena anterior.

4. Ver texto - botão que possibilita ao usuário visualizar a legenda enquanto as cenas são narradas.

5. Controle de volume - através de um botão o usuário pode alterar o volume do áudio, arrastando-o para um volume maior ou menor.

6. Barra de navegação - Possui botões de controle de navegação, além de Menu, Ajuda e Créditos.

\section{2 Área de Conteúdo}

Neste espaço é veiculado o conteúdo do objeto de ensino-aprendizagem. Como forma de estabelecer uma comunicação com o usuário e aprimorar sua experiência, toda a transmissão deste conteúdo ocorre a partir de animações; estas são constituídas a partir de representações de uma situação problema, ilustrando conceitos centrais e exemplificando situações práticas (figura 5) 
Figura 5: Algumas animações desenvolvidas para o projeto CME (llustração: Marcel Junges e Bruno Muller)

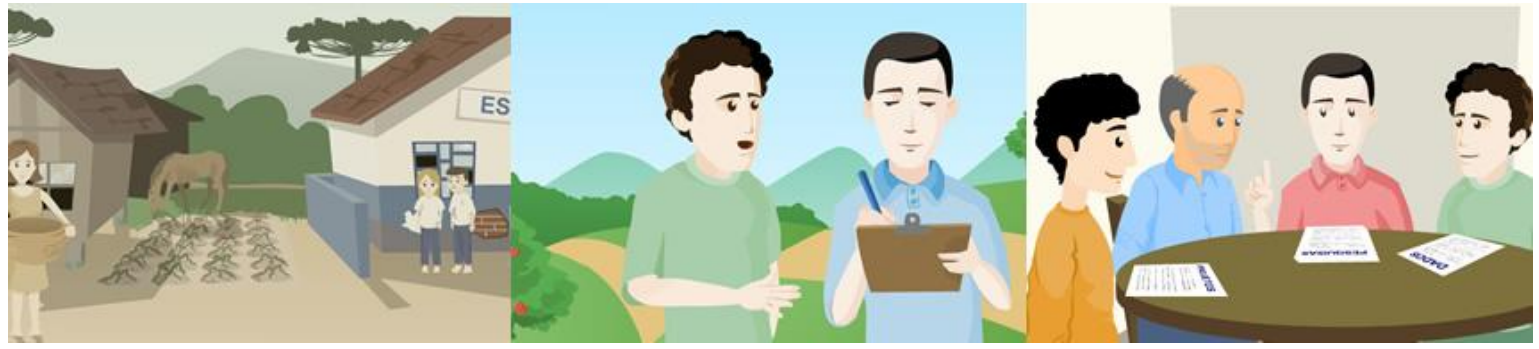

Para o desenvolvimento destas animações, foram realizados storyboards, ou seja, planificações dos quadros principais, as cenas, para, a partir deste estudo, desenhar objetos e personagens e colocá-los em movimento. Optou-se por utilizar animações em virtude da fácil compreensão por parte dos usuários, evocando o aspecto estético no sentido de representação gráfica de locais mais pobres (primeira parte figura 5), relacionada ao tema de campo (segunda parte figura 5), sob a aparência e emoção dos personagens (terceira parte figura 5). Estes aspectos denotam a importância da estética da informação, associada à temporalidade, responsável pela experiência do usuário.

Como alternativa para conteúdos textuais, inerentes ao projeto, foi proposta a utilização de uma metáfora de um livro, possibilitando ao usuário uma rápida associação simbólica. Desta forma, a concisão objetiva é utilizada através do repertório do usuário. Para esta seção, projetou-se também uma sub-navegação, com o intuito de propiciar ao usuário uma navegação por entre as páginas do livro (figura 6), facilitando assim sua experiência.

Figura 6: Utilização do livro como metáfora

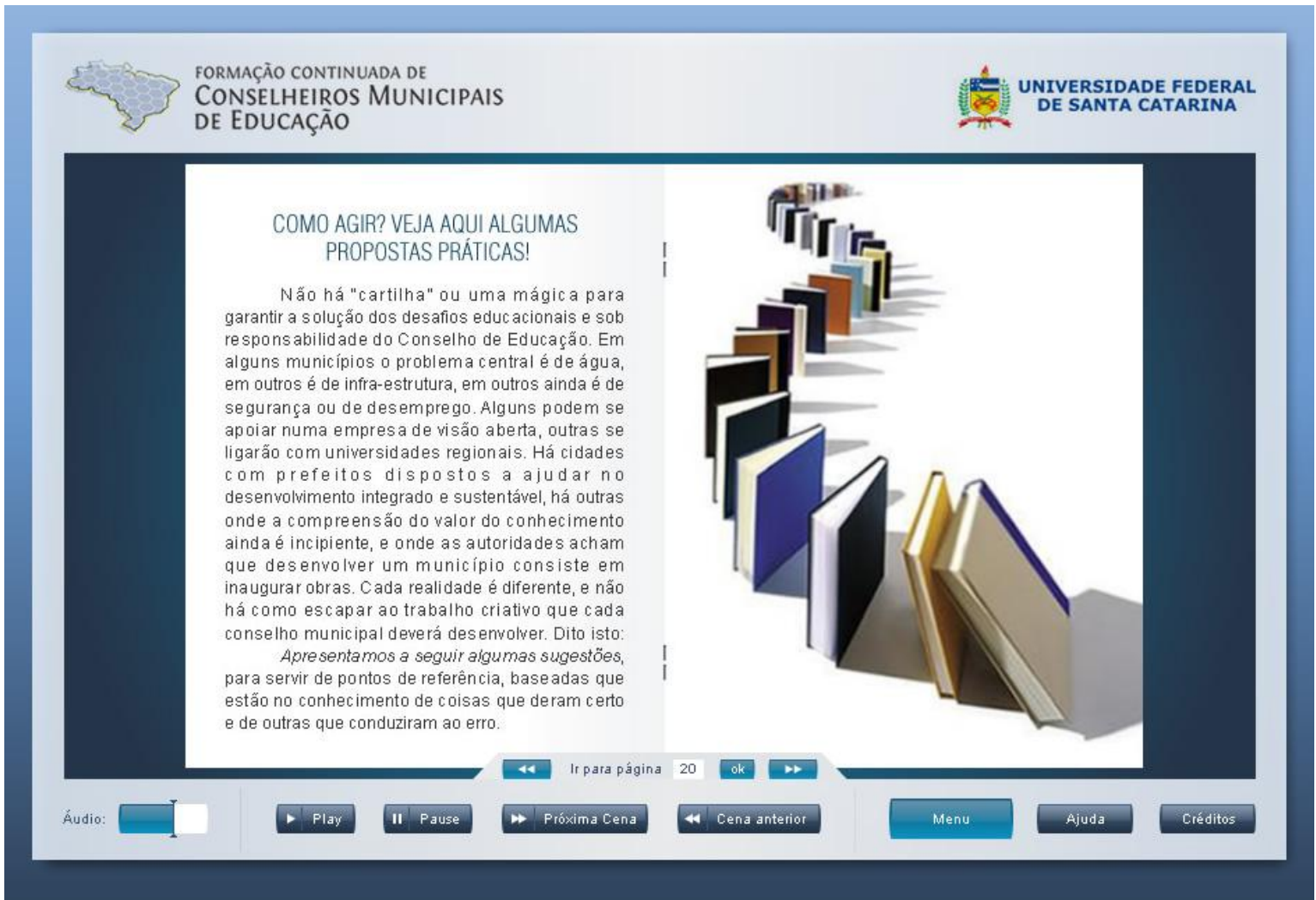

\subsection{Botão Ver texto}

Este botão surgiu como uma alternativa de acessibilidade à usuários surdos. A maior parte das animações dispostas na área de conteúdo possui áudio, com narrações e/ou diálogos. Caso o usuário desejar ver o texto que está sendo narrado, basta clicar no botão "Ver texto", e surgirá um retângulo branco semitransparente, com o texto corrente (figura 7). O fato do retângulo não ser totalmente opaco informa ao usuário que existe o conteúdo (animação) no plano posterior. Isto 
denota mais um exemplo de como a estética está diretamente relacionada ao design de informação.

Figura 7: Botão Ver Texto

Organizaram-se, e com os meios de que dispunham fizeram parcerias com instituiçôes de pesquisa, formaram cooperativas, abriram canais conjuntos de comercialização para năo depender de atravessadores, e hoje constituem uma das regiỏes que mais rapidamente se desenvolve no pais.

\subsection{Barra de Navegação}

A barra de navegação compreende os botões Play, Pause, Próxima Cena e Cena Anterior, responsável pela navegação linear na área de conteúdo. Deste modo, o usuário pode facilmente saltar de uma cena para outra, ou até mesmo parar a animação. Posteriormente, encontra-se o botão de Menu, responsável pela navegação não-linear, onde o usuário pode escolher uma cena qualquer na hipermídia, acessando a mesma. Neste menu são relacionadas miniaturas das cenas, a fim de facilitar a compreensão da informação pelo usuário. Relacionado à impressão estética e à experiência, é necessário que os botões possuam um aspecto que os diferencie, caracterizandoos como botões. Criar estados para os mesmos, como Rollover (mouse sobre o botão) e Rollout (tirar o mouse do botão) propiciam ao usuário um engajamento mais preciso.

Figura 8: Barra de Navegação

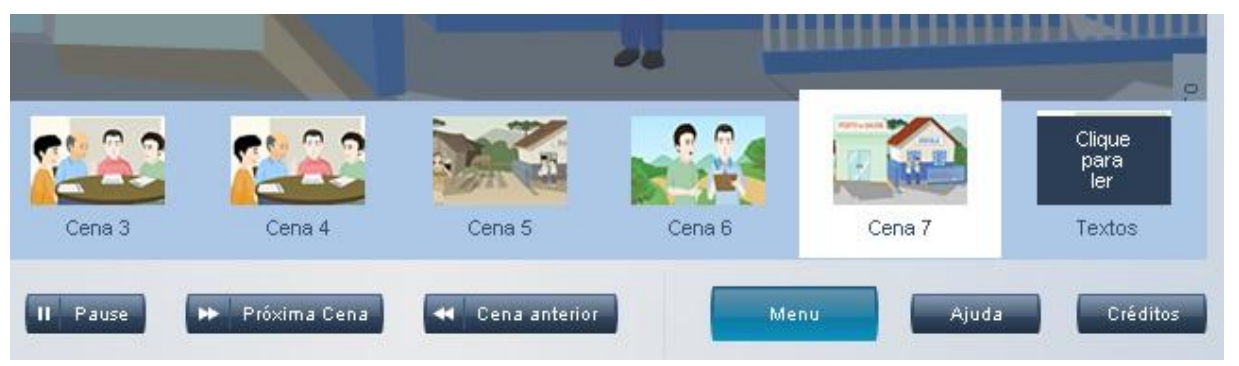

Dentro da barra de navegação também encontra-se o botão Ajuda. Esta seção da hipermídia foi criada com o intuito de propiciar o suporte adequado ao usuário, caso o mesmo possua dificuldades de navegação ou compreensão de como o sistema se comporta. Para transmitir a informação, foi utilizado um artifício estético, colocando em destaque a área onde se deseja transmitir a informação (figura 9).

Figura 9: Ajuda 


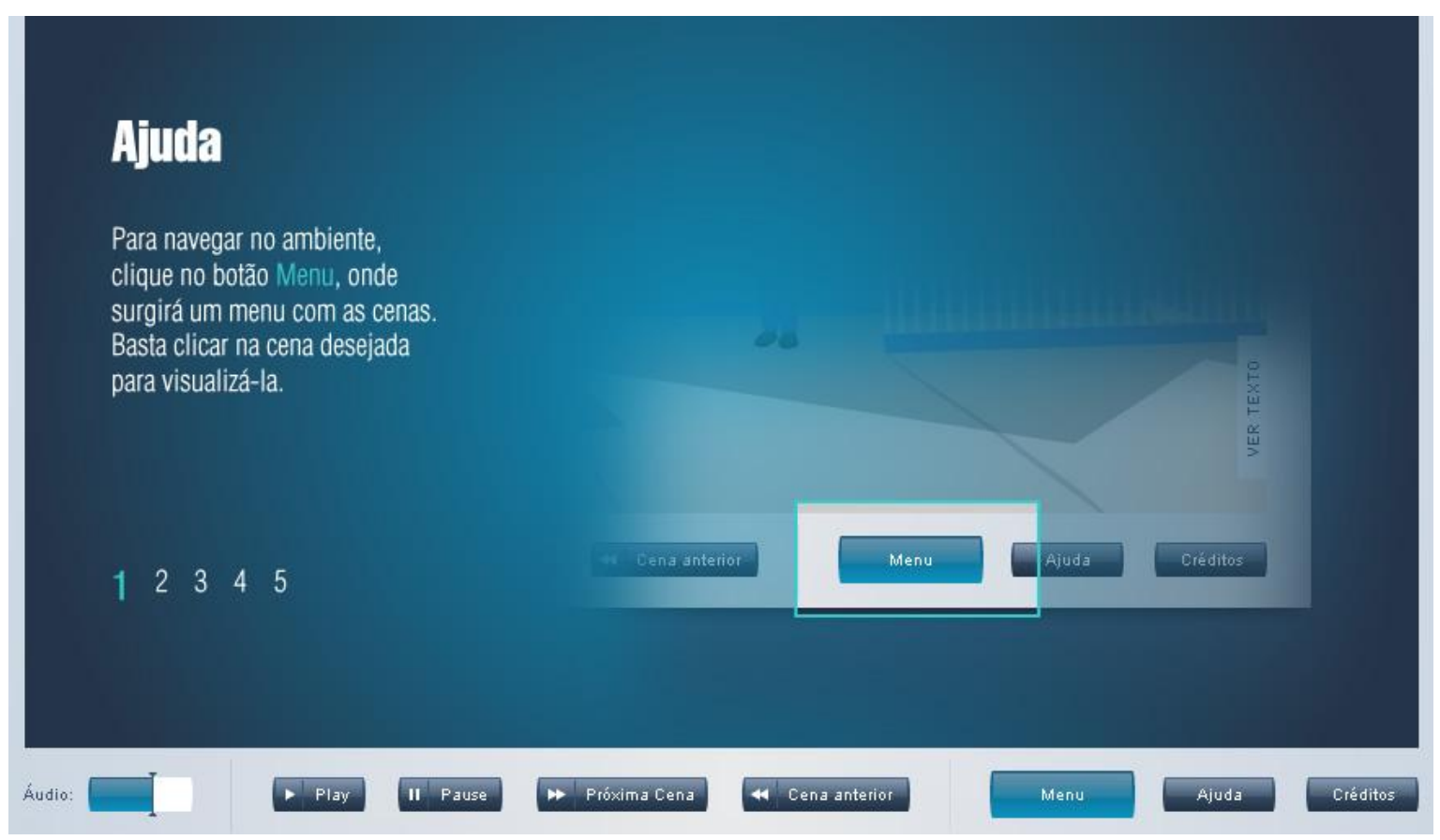

\section{Conclusão}

Através do desenvolvimento e análise do projeto Formação Continuada de Conselheiros Municipais de Educação, foi discutida a importância da impressão estética e experiência do usuário relacionado ao desenvolvimento de hipermídias, neste caso um objeto de ensinoaprendizagem e sua pertinência ante o design de informação. A informação intrínseca a impressão estética é uma importante ferramenta para o designer no desenvolvimento de seus projetos, visto que é responsável pelo primeiro contato da interface com o usuário. Compreender como e de que forma expressar a informação através da estética e do incremento da experiência do usuário aqui discutidos resulta em diretrizes da utilização destes elementos na composição e organização do design da informação. Noções acerca do equilíbrio estético, bem como a categorização e experiência estética servem como instrumentos para o designer na concepção de objetos de ensino-aprendizagem, assim como hipermídias em geral.

A impressão estética nos websites é um diferencial para o usuário e se esta, associada à experiência, engajar seu público, a interação irá ocorrer e a mensagem hipermidiática será transmitida com sucesso. Esta mensagem, especialmente nos objetos de ensino-aprendizagem, torna-se fundamental para a compreensão/entendimento do aluno ante o conteúdo apresentado.

Com o crescimento da tecnologia, e talvez de novas possibilidades de interfaces, como IPhone, GPS, Surface,entre outras, surge ao designer o desafio de traduzir estes conceitos relacionados à estética frente à novas possibilidades de experiência para o usuário e objetos de ensinoaprendizagem.

\section{Agradecimento}

Participantes deste projeto:

Esse projeto foi desenvolvido com o MEC Seed sob orientação de Simone Medeiros e executado pelo LANTEC/CED/UFSC com a coordenação de Roseli Zen Cerny e pelo HiperLab/CCE/UFSC com a coordenação de Alice T. Cybis Pereira.

Equipe Lantec: Roseli Zen Cerni, Andrea Lapa, Isabella Benfica, Cláudia Kautzmann, Paulo Mecksenas e Jessica Schiller.

Equipe Hiperlab: Alice T. Cybis Pereira, Berenice Santos Gonçalves, Marília Matos Gonçalves, Tobias Mülling, Israel Braglia, Bruno Panerai Velloso, Ronnie Fagundes de Brito, Marcel Junges e Bruno Muller. 
InfoDesign | Revista Brasileira de Design da Informação / Brazilian Journal of Information Design

\section{Referências}

Artigos em revistas acadêmicas/capítulos de livros

Baeta Neves, A. Q. 2006. Novos Encantamentos: Hipermídia e Motivação. In: $7^{\circ}$ Congresso Brasileiro de Pesquisa e Desenvolvimento em Design. Anais do 70 Congresso Brasileiro de Pesquisa e Desenvolvimento em Design. Curitiba.

Moura, M. 2006. A Interatividade no Design de Hipermídia. In: $7^{\circ}$ Congresso Brasileiro de Pesquisa e Desenvolvimento em Design. Anais do $7^{\circ}$ Congresso Brasileiro de Pesquisa e Desenvolvimento em Design. Curitiba

Livros e material não publicado

Garrett, J. 2003. The Elements of User Experience: User-Centered Design for the web. New Riders.

Crilly, N.; Moultrie, J.; \& Clarkson, J. 2004. Seeing things: consumer response to the visual domain product design. Cambridge. Disponível em: <http://wwwedc.eng.cam.ac.uk/ nc266/seeing_things.pdf> Acessado em: nov 2007

Dondis, D. A. 1991. Sintaxe da Linguagem Visual. Martins Fontes.

Guimarães, L. 2000. A cor como informação. São Paulo. AnnaBlume.

Johnson, S. 2001. Cultura da interface: como o computador transforma nossa maneira de criar e comunicar. Rio de Janeiro. Jorge Zahar Editor.

Löbach, B. 2001. Design Industrial: bases para a configuração dos produtos industriais. São Paulo. Edgard Blücher.

Pirauá, J. 2007. TAE.web-u \{ A construção de uma técnica para avaliação estética de websites com usuários. Dissertação de mestrado. Universidade Federal de Pernambuco.

Shedroff, N. (2001). Experience Design 1, Indianapolis (IN): New Riders.

\section{Sobre os autores}

\section{Tobias Tessmann Mülling}

Possui graduação em Design Gráfico pela Universidade federal de Pelotas. Atualmente faz parte do programa de pós graduação (mestrado) em Design Gráfico da Universidade Federal de Santa Catarina. Trabalha como diretor de arte da Conrad-caine Media Applications $\mathrm{GmbH}$, onde trabalha com clientes como Siemens, Microsoft, Baldessarini, Otto International entre outros. Possui interesse na área de design de experiência, hipermídia e estética.

tmulling@gmail.com

\section{Alice Theresinha Cybis Pereira}

Possui graduação em Arquitetura e Urbanismo pela Universidade Federal e Pós-Doutorado pela University of Sheffield (1992). Atualmente é professora associada I da Universidade Federal de Santa Catarina. Tem experiência na área de Arquitetura e Urbanismo, com ênfase em CAD, atuando principalmente nos seguintes temas: ambiente virtual de aprendizagem, hipermídia, arquitetura sustentável e projeto assistido por computador. É coordenadora do Hiperlab - UFSC. acybis@gmail.com 